\title{
Da infância ao amadurecimento: uma reflexão sobre rituais de iniciação
}

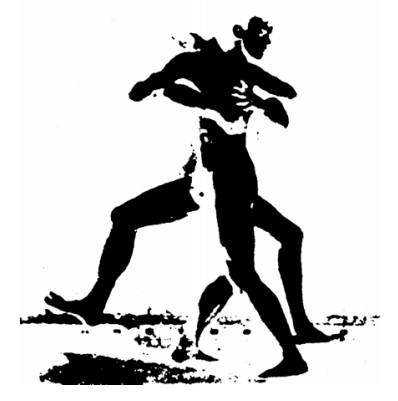

Lucia Helena Rangel ${ }^{1}$

${ }^{2}$ As classes de idade não são definidas dessa forma por todos por todas as sociedades indígenas. Diversas nomenclaturas remetem para classificações mais detalhadas, designando com termos específicos faixas etárias intermediárias, tais como: crianças que ainda não andam, crianças que andam até os primeiros sinais de puberdade, jovens em processo de iniciação, casados sem filhos, casados com um filho, com mais de um filho, avós com um neto, com mais de um neto. Dado que a variação classificatória é muito grande, adotou-se, neste trabalho, a forma de classificação em três classes de idade para facilitar a exposição.
Problema comum a todas as sociedades humanas é a passagem da infância para a idade adulta. Pode-se constatar que os processos de socialização $e$ educação das crianças têm como finalidade última a formação do adulto homens e mulheres. Essa afirmação óbvia, não é, por outro lado, banal; refere-se ao fato de que a formação da pessoa requer de cada sociedade um conjunto de práticas sociais associadas às referências culturais em vigor, que implicam na eleição de estratégias e objetivos a respeito da pessoa que se quer formar. O que é ser homem, mulher, cidadão, trabalhador? Para que se forme o ser social, as sociedades despendem grandes esforços e a questão ocupa uma dimensão bastante significativa na vida em comum.

Nas sociedades estratificadas, os adultos não serão somente homens $e$ mulheres; serão cidadãos, com maior ou menor poder de interferência política, exercerão profissões variadas, terão poder aquisitivo diferenciado em conseqüencia de pertencer a uma determinada classe social, como é o caso, por exemplo, nas sociedades capitalistas.

Já em sociedades não estratificadas em classes, os adultos serão homens $e$ mulheres em pleno exercício de suas funções sociais, produtivas $e$ reprodutivas. Entre os povos indígenas que vivem em território brasileiro, por exemplo, pode-se dizer, de forma genérica, que o modelo de sociabilidade está baseado, de um certo ponto de vista, em uma correspondência entre o ciclo da vida e as funções e papéis exercitados pelos indivíduos. Desse modo as etapas etárias - infância, maturidade e velhice equivalem a posições sociais bem definidas².

As categorias de homens e mulheres maduros podem ser identificadas pelas funções e status mais importantes que assumem: casamento, procriação $e$ produção. É possível afirmar que a maior parte do trabalho social realizado

\footnotetext{
${ }^{1}$ Antropóloga, professora do Departamento de Antropologia da Faculdade de Ciências Sociais e Programa de Estudos Pós-graduados em Ciências Sociais da Pontifícia Universidade Católica de São Paulo, PUC-SP. Conselheira da Comissão Pró-Índio de São Paulo. Assessora do Conselho Indigenista Missionário. E-mail: lurangel@pucsp.br
} 
cabe a essa categoria de indivíduos: caça, pesca, agricultura, coleta, construções, fabricação de instrumentos e utensílios, objetos de adorno e cerimoniais, preparo e cocção de alimentos. Crianças e idosos também trabalham, mas em intensidade diferenciada, de acordo com sua capacidade. Isso quer dizer que o esforço despendido pelos adultos é o elo de um sistema de reciprocidade cujo sentido é isentar do trabalho os mais velhos e formar a força de trabalho que assumirá a carga mais intensa no futuro.

Aos indivíduos mais idosos reserva-se um papel especial relativo à função da palavra forte; sua sabedoria é o continente da experiência da vida, dos ritos, dos mitos, dos valores e das crenças. Sonhos, visões, opiniões dos mais velhos constituem a referência de respeito adotada por todos os membros de uma comunidade. Na sociedade Jamamadi, por exemplo, entoam cantos, contam mitos e histórias de aventura, especialmente dirigidos às crianças, deixando transparecer uma atitude intencionalmente educativa. Sua palavra é forte no âmbito das decisões políticas tomadas pelos adultos. Os velhos são aqueles que viveram mais, por isso sabem mais, e essa condição é fundamental nas sociedades baseadas na tradição oral.

As crianças são seres em formação, devem aprender as coisas da vida $e$ preparar-se para os papéis sociais que assumirão no futuro. A socialização das crianças é fortemente marcada pelo treinamento dos papéis e funções referentes ao sexo ao qual pertencem. O trabalho social é dividido entre os sexos, de modo que tarefas masculinas e femininas complementam-se nas relações de produção. Há também marcas distintas no desempenho das funções rituais, na responsabilidade educativa e em todos os âmbitos da vida social, o que faz com que muitos antropólogos concordem com a afirmação de que a esfera doméstica é domínio feminino e a esfera pública, domínio masculino. Mesmo que não haja uma fragmentação tão excludente entre o público e o doméstico, a divisão sexual do trabalho e das funções rituais estão no centro da dinâmica da vida social. Os exemplos são abundantes, mas para citar os mais comuns, em diversas sociedades aos homens cabem tarefas como caça, pesca, construção de casas, derrubada de mato e limpeza de terreno para plantio $e$ às mulheres colheita, cocção de alimentos, corte de lenha, coleta, carregar a tralha nos deslocamentos da família. As mulheres Jamamadi são "donas" das roças, os homens fazem as roças para suas mulheres. Em diversos momentos do cerimonial Xavante as mulheres não podem participar, sequer podem ver de longe o desenrolar do ritual sob pena de serem castigadas por espíritos terríveis. Em outros momentos homens e mulheres cooperam no trabalho e participam de rituais coletivamente. O processo educativo das crianças é, portanto, um treinamento constante e contínuo de aprendizagem das tarefas e do modo de ser masculino ou feminino.

Ao lado da assimilação paulatina de valores e referências culturais mais gerais, as crianças são treinadas pelo método da imitação. Não há formalidade no processo educativo, a criança imita o adulto, a menina a mãe e o menino o pai, fazendo o que ele faz. O pai confecciona um pequeno arco e flechas para seu filho, que passa a utilizá-lo desde cedo para que possa adquirir habilidades de caçador. As crianças brincam de representar as histórias míticas, rindo muito e, por vezes até debochando. Nessas brincadeiras imitam os adultos, o velhos, os animais e os espíritos, em suas maneiras de falar, em suas posturas corporais, e tudo é motivo de riso. $\mathrm{E}$ 
assim treinam e aprendem o que devem ser e fazer quando forem adultos. O sentido da educação é a formação do ser independente. Um homem ou uma mulher deve saber todas as tarefas e adquirir todas as habilidades que The são próprias. A responsabilidade para que, no futuro, uma criança seja um adulto pleno é da família. Não há, portanto, transferência de funções para nenhuma instituição externa, formal ou disciplinar. Ao contrário, o tipo de vida próprio dessas sociedades exige que o indivíduo seja criativo, saiba resolver problemas com presteza, saiba retornar para casa depois de um dia na mata, saiba defender-se de animais que atacam, saiba construir e fabricar o que quer que seja para sua comodidade e de sua família, conheça plantas, animais e fenômenos naturais, e tenha bem claras as referências culturais de seu povo porque um dia, em idade avançada, serão os pilares da memória coletiva, mesmo que recriada em função das mudanças que a história impõe. A formação da pessoa adulta é o foco do processo de socialização $e$ educação; e isto não é exclusividade das sociedades indígenas. Cada sociedade elege o modo e o momento de transformar uma criança em um ser adulto. Em nossa sociedade construímos um padrão de sociabilidade que passou a incluir, em tempos recentes, uma fase intermediária chamada adolescência. Essa etapa da vida não corresponde, necessariamente, a uma fase biológica definida; criamos, na verdade, uma fase psicológica cuja finalidade é adiar a transformação da criança em adulto. Os avós das pessoas adultas de hoje casavam-se com idade entre 13 e 18 anos; muito comum era o casamento entre uma moça de 15 e um rapaz de 18 anos. A adolescência tem sido cada vez mais ampliada para certas camadas sociais, em nossa sociedade. O retardamento do início das funções produtivas é um dos fatores mais importantes que explicam o fenômeno; quer seja pela falta de empregos, quer pelas exigências de formação profissional cada vez mais especializada, as camadas mais altas da hierarquia social dependem da instituição escolar para alongar a adolescência de seus filhos, deixando-os no limbo da indefinição juvenil, às vezes por mais de dez anos. Por outro lado, nas camadas sociais mais baixas o fenômeno inverte-se, exigindo de crianças de 7, 10 ou 12 anos que abandonem a escola para trabalhar, porque precisam contribuir para o orçamento familiar, mesmo que seja em troca de salários irrisórios. Esses exemplos rápidos mostram que nossa sociedade não possui critérios nítidos para promover a passagem da infância para a idade adulta, porque a adolescência é vivida de maneira diferenciada pelos jovens de classes sociais distintas. Ao que tudo indica, há um padrão psicológico idealizado que faz com que todos os jovens sejam tratados como imaturos, irresponsáveis e em crise constante; mas não há um padrão sociológico comum, que estabeleça obrigações, direitos e atividades típicas dessa fase intermediária.

Existem cerimônias que cumprem funções rituais, mas que, no entanto, não marcam definitivamente a passagem: os jovens passam por diversas formaturas, são calouros e veteranos em duas ou três etapas da trajetória escolar, tiram documentos, votam, prestam exames de habilitações, comemoram os aniversários de 15 e 18 anos, compram ou ganham o primeiro sutiã, a primeira camisinha e, tudo isso, pode ser mais ou menos ritualizado nos contextos familiares e escolares. O fato é que não existe uma referência clara a respeito do marco temporal de passagem. É comum que o jovem clame aos pais que já possui 18 anos e, portanto, pode viajar sozinho; 
porém, ainda se deixa levar de automóvel até para ir à escola. A indefinição prolonga-se, a dependência desdobra-se por tempo bastante elástico. Isso mostra que em cada época e em cada lugar há uma maneira específica de marcar o momento de passagem para a idade adulta. $\mathrm{O}$ casamento, a procriação $e$ as responsabilidades produtivas, somados a outras características de status, obrigações e direitos, definem essa categoria de pessoas que constitui a força maior da reprodução da vida social. $\mathrm{O}$ problema é o estabelecimento, por parte da sociedade, do quando e do como se forma um adulto. Em sociedades, como a brasileira, que não consegue firmar com todos os seus membros o contrato social, porque bloqueia a muitos o acesso aos recursos e ao trabalho, dificilmente poderia ter um marco preciso para a promoção do adulto.

Nas sociedades indígenas, a adolescência não é uma fase nem social nem psicológica, porque não é necessária. O corpo dos jovens está apto para a procriação e em seu processo educativo já treinou a aquisição das habilidades práticas pertinentes ao seu gênero sexual; portanto, cabe à sociedade promover sua transformação em adulto. Neste sentido, para completar sua socialização, essa passagem é realizada através de um ritual de iniciação que é um dos mais importantes no ciclo cerimonial. As marcas corporais femininas, a primeira menstruação especialmente, são o indicativo do momento que o ritual deve acontecer. Os rapazes, cujas marcas corporais são menos nítidas, mas que regulam em idade com as meninas que nasceram em período próximo a eles, são identificados por sua estatura, produção de esperma e, muitas vezes, entram em processo ritual muito cedo a partir de nove ou 10 anos. Os rituais de iniciação dos jovens podem durar de um a cinco anos, dependendo de como cada sociedade elabora o processo ${ }^{3}$.

Esse é um momento delicado, a mudança de estado não tem retorno. Ao completar o ciclo ritual, a criança será adulta, pronta para casar, procriar e realizar a reprodução social. Em muitos casos, os rituais iniciáticos dos jovens encerram-se com a cerimônia de casamento.

Os rituais de iniciação das mulheres, em geral, implicam um longo período de reclusão, durante o qual as moças quase não saem de casa, chegando até a perder a cor bronzeada da pele por falta de sol; ou saem da reclusão, desbotadas e com os cabelos longos, cobrindo o rosto. Durante um tempo que pode durar de seis meses a dois anos, ou até mais, a contar da primeira menstruação, a moça é recolhida em um espaço reservado dentro de sua casa (um biombo pode ser a delimitação desse espaço), de onde sairá apenas para satisfazer necessidades fisiológicas; é o tempo de aprender a lidar com sua menstruação, de fixar os tabus menstruais, alimentares e outros, repassar conhecimentos e confeccionar os objetos femininos, como se fosse o seu enxoval: redes de dormir para ela e o futuro marido, cestos de carregar, panelas de cerâmica, colares próprios das mulheres adultas, dependendo sempre de qual seja a tradição cultural. Ouvem muitas histórias, conversam com as mulheres mais velhas, enfim, preparam-se para as futuras responsabilidades.

Os rituais de iniciação masculinos compõem-se, especialmente, de um conjunto de provações físicas e emocionais, fixação de conhecimentos, valores, crenças etc. Na sociedade Xavante, por exemplo, existe a casa dos solteiros para onde se dirigem os meninos em processo iniciático. Essa casa pode estar localizada no pátio da aldeia, portanto, à vista $e$ ao alcance de

\footnotetext{
${ }^{3}$ Nas referências bibliográficas estão indicadas obras que descrevem cuidadosamente os processos rituais peculiares a algumas sociedades indígenas que habitam o território brasileiro.
} 
todos, mas na qual está proibida a entrada das mulheres, que só vão lá para levar alimentos. Durante a iniciação, os meninos podem freqüentar a casa de sua mãe, mas do ponto de vista simbólico, a permanência na casa dos solteiros representa a separação entre o filho e a mãe e, portanto, o preparo para o relacionamento com outra mulher, com quem terá filhos e partilhará responsabilidades familiares.

A formação do homem adulto e sua incorporação no universo masculino exige diversos testes de virilidade, força física, domínio das emoções, em particular do medo, e constante aprimoramento das habilidades básicas que o trabalho requer, assim como a assimilação das regras e valores culturais. Desse modo, os meninos passam por uma série de provações que podem incluir atividades, tais como: passar uma ou mais noites sozinho na mata, levar muitas picadas de formigas, permanecer dentro da água, movimentando os braços por longo período de tempo, pisar em brasas, correr durante dias consecutivos, inscrever tatuagens, perfurar partes do corpo, submeter-se a diversas formas de dor $e$ medo, realizar caçadas difíceis. Enfim, a variedade dessas atividades é grande; cada povo elege algumas, mas são consoantes com o seu modo de vida $e$ referem-se à inscrição, no corpo, do universo da cultura.

Um outro aspecto importante de ser apontado é que esse processo diz respeito à construção da personalidade do indivíduo. Homens e mulheres não são categorias indiferenciadas, além das características gerais advindas da divisão sexual do trabalho, pertencem

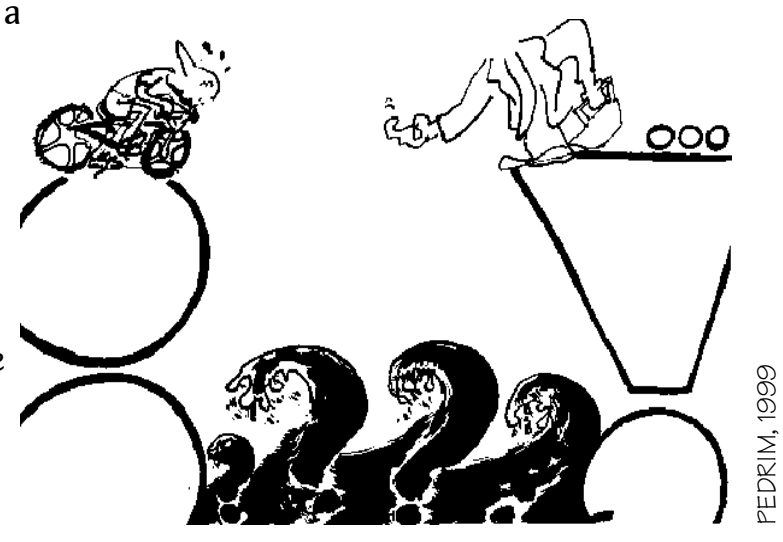
a grupos familiares distintos, cada um com ancestrais míticos e totêmicos próprios que conferem aos indivíduos do grupo um modo de ser especial. Os heróis e/ou totens transmitem também herança de comportamento e de temperamento. Desse modo, cada indivíduo elabora sua idiossincrasia a partir das referências de gênero, família $e$ características pessoais, além, evidentemente, das relações de alteridade em cada um desses níveis.

Os rituais de iniciação, relativos à mudança de estado da infância para a maturidade, praticamente, encerram o processo de educação básica. $\mathrm{O}$ adulto não está pronto e acabado neste momento, seu processo de socialização é contínuo, até a morte; é preciso saber viver e morrer, saber envelhecer e assumir papéis e funções diferenciadas ao longo da vida, porém, o momento de passagem para o estado maduro é crucial, dado o sentido social que é atribuído a essa categoria de pessoas. O adulto deve ser independente, capaz de desempenhar todas a tarefas e resolver todos os problemas que se lhe apresentem em situações esperadas ou inesperadas, evidenciando-se relações de dependência e complementaridade apenas entre homens e mulheres. A única especialização presente diz respeito às funções do xamã ou pajé, ou de alguns indivíduos detentores de habilidades espirituais especiais, que não são de domínio generalizado, porque não são aptidões adquiridas, mas configuram-se como dons atribuídos por poderes 
sobrenaturais. Enfim, é possível afirmar que esse é um modelo de sociedade na qual o vínculo de pertencimento, dado pelo nascimento ou pela criação de um indivíduo dentro do grupo, é o único canal de participação na vida social $e$ de acesso a todos os bens e recursos disponíveis, cabendo ao indivíduo o desenvolvimento de habilidades para a obtenção de comodidades, bens $e$ prestígio. Ninguém, ou alguma instituição, fará nada por ele, mas, também, não haverá nenhum impedimento para que conquiste a posição almejada. A não ser quando se trata de posições políticas de prestígio que dependem do estabelecimento de alianças e do consenso coletivo.

Talvez, por isso mesmo, os rituais de iniciação sejam tão rígidos e, no caso masculino, as provações apresentem-se com certa dose de crueldade ou violência, ao menos aos nossos olhos que estranham as culturas alheias. Esses rituais são comandados pelos homens mais velhos, pelos pais, tios, irmãos, primos ou padrinhos, cujos papéis são diversos durante o período iniciático. Os mais velhos estão sempre atentos, fazendo-se respeitar quando julgam estar sendo excessivas as exigências com os iniciados.

Termino esta reflexão contando um caso que pode nos aproximar um pouco dos significados do mundo indígena.

Em uma aldeia do povo Jamamadi não se realizam mais os ritos iniciáticos da forma tradicional, mas uma série de acontecimentos ajudam a revelar o sentido da educação e da socialização dos meninos:

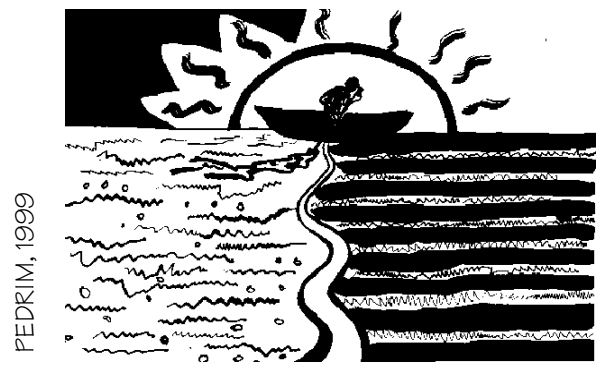

num certo dia, um menino que devia ter, na ocasião, 12 anos mais ou menos, pega uma canoa sozinho e rema igarapé acima. O Igarapé Capana, afluente do rio Purus, é profundo, cheio de curvas fechadas e com muita correnteza. $\mathrm{O}$ menino saiu por volta do meio-dia e ao final da tarde ainda não havia retornado. Seus pais começaram a externar preocupação; passa o tempo, a noite se aproxima e a apreensão toma conta de todos, mas ninguém faz nada, ninguém sai atrás do menino, só esperam. Não há clima de desespero, só expectativa e preocupação; compasso de espera. A noite cai e, de repente, ouve-se um grito de comunicação que ecoa da direção do igarapé.

Contentamento geral, todos correm para a margem; é o menino que chega, ouvindo a fala eufórica do pai - "ele conseguiu, ele conseguiu!”. O menino é recebido com gritos e ovações, está se transformando num homem. O pai passa os dias seguintes contando orgulhoso a aventura do filho, repetindo sempre - "ele conseguiu".

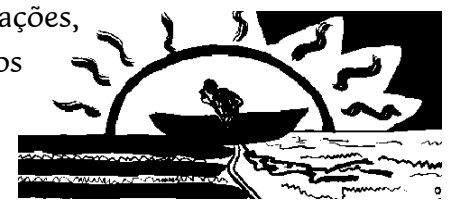

Textos para referência:

GENNEP, A. Os ritos de passagem. Petrópolis: Vozes, 1977. JUNQUEIRA, C. Os índios de Ipavu. São Paulo: Ática, 1978. MAYBURY-LEWIS, D. A sociedade Xavante. Rio de Janeiro: Francisco Alves, 1984.

VIDAL, L. Morte e vida de uma sociedade indígena brasileira: os Kayapó-Xicrin do rio Cateté. São Paulo: Hucitec; Edusp, 1977.

PALAVRAS-CHAVE: ritos de passagem; sociedades indígenas 